\title{
Antibacterial Activity Against Multidrug-Resistant Staphylococcus aureus and in Silico Evaluation of MepA Efflux Pump by Cinnamaldehyde Chalcone
}

\author{
Jayze da Cunha Xavier ${ }^{1(D)}$, Thiago Sampaio de Freitas ${ }^{1(D)}$, Priscila Teixeira da Silva ${ }^{1(D)}$, Henrique \\ Douglas Melo Coutinho ${ }^{\text {1D }}$, Alexandre Magno Rodrigues Teixeira ${ }^{1}$ (D), Leilane Gomes Rodrigues ${ }^{2}$ (D), \\ Paulo Nogueira Bandeira 2(D), Carlos Emídio Sampaio Nogueira 3(D), Larissa Santos Oliveira 4(D), \\ Emmanuel Silva Marinho 4(iD, Hélcio Silva dos Santos 1,2,4,* (D)
}

1 Department of Biological Chemistry, Regional University of Cariri, Crato, CE, Brazil; jayzecx @ gmail.com (J.C.X.); thiagocrato@hotmail.com (T.S.F.); pi.teixeiradasilva@gmail.com (P.T.S.); carlosemidio@ymail.com (C.E.S.N.); hdmcoutinho@gmail.com (H.D.M.C.); alexandre.teixeira@urca.br (A.M.R.T.);

2 Science and Technology Centre - Chemistry Course, State University Vale do Acaraú, Sobral, CE, Brazil; bandeirapn@yahoo.com.br (P.N.B.); leilanegr16@gmail.com (L.G.R.);

3 Department of Physics, Regional University of Cariri, Juazeiro do Norte-CE, Brazil

4 Science and Technology Center, Postgraduate Program in Natural Sciences, State University of Ceará, Fortaleza, CE, Brazil; larissa_as10@hotmail.com (L.S.O.); emmanuel.marinho@uece.br (E.S.M.);

* Correspondence: helciodossantos@gmail.com (H.S.S.)

Scopus Author ID 15819042100

Received: 8.10.2021; Revised: 5.11.2021; Accepted: 8.11.2021; Published: 25.11.2021

\begin{abstract}
Phytochemical studies on Croton species have identified the presence of secondary metabolites responsible for a wide variety of pharmacological activities, among them antimicrobial activity. Research for new substances with antimicrobial activity derived from natural products can give a major contribution to human health worldwide by finding more efficient and fewer toxic formulas in the race against pathogenic microorganisms' resistance. Among bacterial pathogens, Staphylococcus aureus species, despite being present in the skin and nasal mucosa, can cause many infections and diseases. These opportunists reach debilitated people in hospitals and are challenging to treat. Here, we performed the structural characterization, determination of antibiotic activity, and MepA efflux pump inhibition potential against $S$. aureus of the chalcone ( $2 E, 4 E)$-1- (2-hydroxy-3,4,6-trimethoxyphenyl)5-phenylpenta-2,4-dien-1-one, derived from natural products 2-hydroxy-3,4,6trimethoxyacetophenone isolated from Croton anisodontus and cinnamaldehyde. The chalcone was synthesized by the Claisen-Schmidt condensation. In addition, microbiological tests were performed to investigate the antibacterial activity, modulator potential, and efflux pump inhibition against the $S$. aureus multi-resistant strains. MIC values obtained to chalcone were not clinically relevant (MIC $\geq$ $1024 \mu \mathrm{g} / \mathrm{mL}$ ). However, chalcone hampers the binding of the antibiotic to the binding site of the MepA efflux pump. It acts as a competitive inhibitor, being expelled from the bacteria in place of the antibiotic and potentiating ciprofloxacin's action against multidrug-resistant bacterial strains of K2068. Therefore, chalcone can be used as a base for substance design with antibiotic modifying activity.
\end{abstract}

Keywords: chalcone; cinnamaldehyde; Staphylococcus aureus; efflux pump.

(c) 2021 by the authors. This article is an open-access article distributed under the terms and conditions of the Creative Commons Attribution (CC BY) license (https://creativecommons.org/licenses/by/4.0/).

\section{Introduction}

Over the years, natural products have been selected with the efficiency and selectivity needed to reach cellular targets and avoid resistance naturally, characteristics that many pure synthetic molecules do not possess. Cinnamaldehyde is a natural $\alpha, \beta$-unsaturated aromatic 
aldehyde found in cinnamon bark oil. It has been reported to have antimicrobial and antibiofilm activities against a wide range of Gram-positive and Gram-negative bacterial pathogens, including Pseudomonas aeruginosa, Escherichia coli, Staphylococcus aureus, Staphylococcus epidermidis, and Streptococcus mutans, and Enterococcus faecalis [1-13]. The antimicrobial and modulatory activity of the natural 2-hydroxy-3,4,6-trimethoxyacetophenone isolated from Croton anisodontus (Figure 1) towards Escherichia coli, Pseudomonas aeruginosa, and Staphylococcus aureus strains have been reported [14]. The results indicated that acetophenone isolated from $C$. anisodontus might be a starting compound for the synthesis of chalcones with antimicrobial activity [15-23].

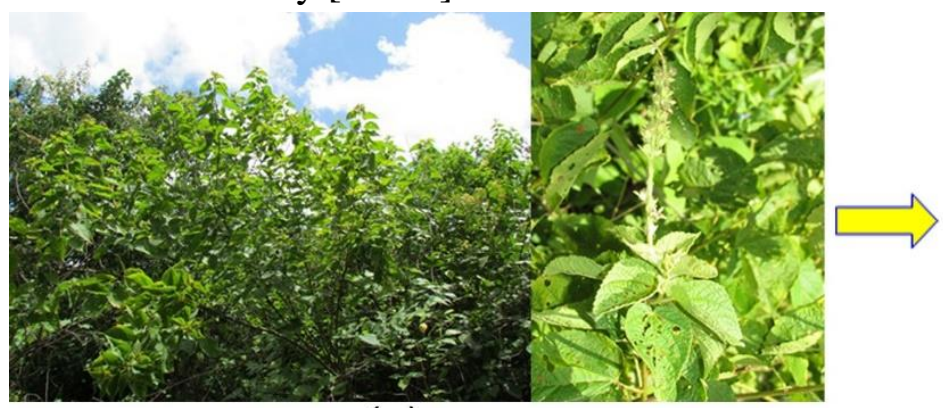

(a)

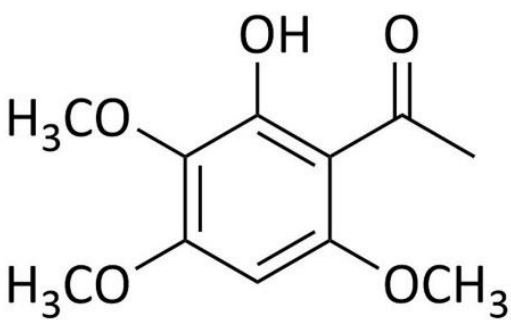

(b)

Figure 1. (a) Aerial parts of C. Anisodontus; (b) 2-hydroxy-3,4,6-trimethoxyacetophenone.

Chalcones have an open chain flavonoid structure in which the two aromatic rings are joined by a three-carbon $\alpha, \beta$-unsaturated carbonyl linker [24]. They can be obtained from natural sources or synthesis and are widely distributed in fruits, vegetables, and tea. This class of compound has aroused much interest due to the broad spectrum of pharmacological activities that they present, including anticancer [25,26], anti-inflammatory [27], and antioxidant [28] properties towards human diseases.

This work aimed to evaluate the antibacterial activity and efflux pump inhibition against $S$. aureus of the chalcone (2E, 4E)-1-(2-hydroxy-3,4,6-trimethoxyphenyl)-5phenylpenta-2,4-dien-1-one synthesized by natural products cinnamaldehyde and 2-hydroxy3,4,6-trimethoxy acetophenone.

\section{Materials and Methods}

\subsection{General procedures.}

Cinnamaldehyde was purchased from Sigma-Aldrich. ${ }^{1} \mathrm{H}$ and ${ }^{13} \mathrm{C}$ NMR were recorded on a Bruker Avance DRX-500 (500 MHz for ${ }^{1} \mathrm{H}$ and $125 \mathrm{MHz}$ for ${ }^{13} \mathrm{C}$ ); chemical shifts were given in $\mathrm{ppm}\left(\delta_{\mathrm{C}}\right.$ and $\left.\delta_{\mathrm{H}}\right)$, relative to residual $\mathrm{CHCl}_{3}(7.24$ and $77.0 \mathrm{ppm})$. The infrared spectrum of the chalcone was measured at room temperature by Attenuated Total Reflectance Fourier Transform Infrared spectroscopy (ATR-FTIR) using a Bruker vacuum infrared spectrometer (FTIR) VERTEX 70V at room temperature in the range of 130 to $4000 \mathrm{~cm}^{-1}$, with a resolution of $2 \mathrm{~cm}^{-1}$.

\subsection{Synthesis of the chalcone.}

The description of the procedure of the synthesis of the chalcone is shown in Scheme 1. The chalcone was synthesized by a Claisen-Schmidt condensation reaction in a basic medium [19]. At ethanol solution of 2-hydroxy-3,4,6 trimethoxyacetophenone (2 mmol) was added to a benzaldehyde solution and the derivatives $(2 \mathrm{mmol})$, followed by the addition of ten 
drops of $50 \% \mathrm{w} / \mathrm{v}$ aq. $\mathrm{NaOH}$ with stirring for $48 \mathrm{~h}$. The solid that formed was filtered under reduced pressure, washed with cold water, and analyzed by TLC.<smiles>COc1cc(OC)c(C(C)=O)c(OC)c1OC</smiles><smiles>COc1cc(OC)c(C(=O)/C=C/C=C/c2ccccc2)c(O)c1OC</smiles>

Scheme 1. Preparation of chalcone. a) $\mathrm{NaOH} 50 \% \mathrm{w} \mathrm{v}^{-1}$, ethanol, t.a., $48 \mathrm{~h}$.

(2E,4E)-1-(2-hydroxy-3,4,6-trimethoxyphenyl)-5-phenylpenta-2,4-dien-1-one: Yellow solid (Yield: $35.4 \%)$, m.p. $144.8-145.2^{\circ} \mathrm{C}$. IV (KBr, $\left.v_{\mathrm{cm}}{ }^{-1}\right): 1634,1600,1588,1575$, 1480, 1167. ${ }^{1} \mathrm{H} \mathrm{RMN}\left(\mathrm{CDCl}_{3}\right.$, ppm): 3.84 (s, MeO); 3.93 (s, MeO); 3.95(s, MeO); 6.99 (s, H5'); 7.44 (m, H-4); 7.38 (d, H-3/5, J = 7,1 Hz,); 7.51 (d, H-2/6, J=7,2 Hz); 7.62 (d, Ha, J=14,6

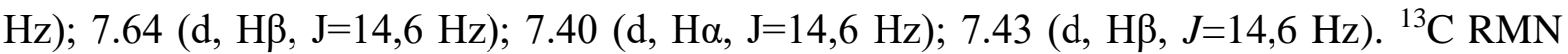
$\left(\mathrm{CDCl}_{3}, \mathrm{ppm}\right): 193.2(\mathrm{C}=\mathrm{O}) ; 60.9\left(\mathrm{MeO}-3^{\prime}\right) ; 56.1\left(\mathrm{MeO}-4^{\prime}\right) ; 56.2\left(\mathrm{MeO}-6^{\prime}\right) ; 107.0\left(\mathrm{C}-1^{\prime}\right) ; 158.7$ (C-2'); 131.0 (C-3'); 159.6 (C-4'); 87.2 (C-5'); 158.5 (C-6'); 136.5 (C-1); 127.7 (C-2/6); 129.1 $(\mathrm{C}-3 / 5) ; 131.0(\mathrm{C}-4) ; 129.2(\mathrm{C} \alpha) ; 143.5(\mathrm{C} \beta) ; 127.0(\mathrm{C} \alpha) ; 141.8(\mathrm{C} \beta)$. MS-EI $m / z=340)$.

\subsection{Bacterial strains.}

Multidrug-resistant S. aureus strains 1199B and K2068 were used in both direct and modulatory antibacterial activity assays. The 1199B strain carries the NorA gene that expresses a protein responsible for the efflux of quinolones, and the K2068 strain is related to the MepA gene, another class of bacterial efflux pumps. Both strains were obtained from cultures grown at the Laboratory of Microbiology and Molecular Biology (LMBM) of the Regional University of Cariri (URCA), Brazil.

\subsection{Drugs.}

The drugs chlorpromazine (CPZ), carbonyl cyanide m-chlorophenylhydrazone (CCCP), and ethidium bromide (EB) were obtained from Sigma Aldrich Co. Ltd. The antibiotics were dissolved in dimethyl sulfoxide (DMSO) and after in sterile water (concentration of 1024 $\mu \mathrm{g} / \mathrm{mL}$ ). Norfloxacin (NorA) and ciprofloxacin (Cip) were the antibiotics used. CPZ and EB solutions were dissolved in distilled, sterile water, stored at $-20^{\circ} \mathrm{C}$, and kept protected from light (concentration of $1024 \mu \mathrm{g} / \mathrm{mL}$ ). The CCCP was dissolved in methanol/water $(1: 1, \mathrm{v} / \mathrm{v})$ and stored at $-20^{\circ} \mathrm{C}$ (concentration of $1024 \mu \mathrm{g} / \mathrm{mL}$ ).

\subsection{Antibacterial activity test by Minimum Inhibitory Concentration (MIC).}

The MIC was determined by microdilution assay using $100 \mu \mathrm{L}$ of each suspended bacterial inoculum in saline solution, corresponding to 0.5 of the McFarland scale, followed by the addition of $900 \mu \mathrm{L}$ of brain heart infusion (BHI) in microtubes $(2 \mathrm{~mL})$. These were then transferred to 96-well microtiter plates, and serial dilutions of each substance were performed with concentrations ranging from 0.5 to $512 \mu \mathrm{g} / \mathrm{mL}$ (1:1). The plates were incubated at $37{ }^{\circ} \mathrm{C}$ for $24 \mathrm{~h}$, and bacterial growth was assessed by using resazurin. The MIC was defined as the lowest concentration in which no growth can be observed [18]. The antibacterial assays were performed in triplicates, and results were expressed as an average of replicates. 
2.6. Evaluation of efflux pump inhibition by MIC reduction.

Briefly, $150 \mu \mathrm{L}$ of each suspended bacterial inoculum in saline solution, corresponding to 0.5 of the McFarland scale, were added to microtubes $(2 \mathrm{~mL})$ together with $1350 \mu \mathrm{L}$ of BHI as a control. In tests, $150 \mu \mathrm{L}$ of each suspended bacterial inoculum in saline solution, corresponding to 0.5 of the McFarland scale, were added together with EPIs (MIC/8) and completed with BHI. These were then transferred to 96 -well microtiter plates, and $100 \mu \mathrm{L}$ of the antimicrobial drug and EB serial dilutions were performed (1:1). The plates were incubated at $37^{\circ} \mathrm{C}$ for $24 \mathrm{~h}$, and bacterial growth was assessed by using resazurin. MIC was defined with antibiotics and EB concentrations ranging from 0.5 to $512 \mu \mathrm{g} / \mathrm{mL}$. The MIC of controls was assessed using antibiotics and EB alone [18].

\subsection{Statistical analysis.}

All bacteriological tests were performed in triplicates. Data were analyzed using a twoway ANOVA followed by Bonferroni's post hoc test (where $p<0.05$ was considered significant). The geometric mean of the triplicates was used as the central data \pm standard error of the mean. The GraphPad Prism 5.0 statistical program was used for the analysis.

\subsection{Docking procedure.}

The MepA model was generated by retrieving the protein sequence for the NCTC 8325 strain from the Uniprot database. Then, the SWISS-MODEL [29] service was used to build the homology model. A total of 50 templates were generated, and the template with the best Global Model Quality Estimation score was based on the structure of the multidrug and toxic compound extrusion transporter of the Bacillus halodurans (PDB-ID: 5C6N). For the docking procedure, which was carried out using the Autodock Vina [30] software, the grid box was defined as an $80 \AA$ x $80 \AA$ x $80 \AA$ box around the geometrical center of the model. Partial Gasteiger charges were added to ligand atoms, non-polar hydrogen atoms were mixed, while all other parameters were kept at their default values. The best results were chosen based on the binding score.

\section{Results and Discussion}

\subsection{Antibacterial activity and potential antibacterial activity.}

Minimum Inhibitory Concentration (MIC) of chalcone were $\geq 1024 \mu \mathrm{g} / \mathrm{Ml}$, and it does not display antibacterial activity against either of the strains compared to the antibacterial effects of the efflux pump inhibitors CCCP (MIC $32 \mu \mathrm{g} / \mathrm{mL}$ ) and CPZ (MIC $=812 \mu \mathrm{g} / \mathrm{mL}$ ) against the K2068 strain. The CCCP modifies the electrochemical gradient of the membrane inhibiting the efflux pumps that need this source of energy. The chlorpromazine (CPZ), by providing an energetic collapse in NorA, consequently impedes the outflow of toxins, antibiotics, and biocides [31]. The CCCP, nevertheless, possesses toxicity to prokaryotes and eukaryotic cells [32]; for this reason, it is important to research new pump inhibitors that do not have this potential.

The decrease in the MIC proves the inhibition of the MepA pump. The results showed that the chalcone did not present chlorpromazine sensitive pump for the bromide, but it shows sensitivity to CCCP. The data also showed that although chlorpromazine did not inhibit the pump, the chalcone inhibited as much as the CCCP. Due to the reversal of the bacterial 
resistance promoted by the inhibition of efflux pumps, there was a relative reduction in the MIC of the two antibiotics in the K 2068 strain, including synergism with the significance of $p$ $<0.001$. The K 2068 strain possesses a pump for ciprofloxacin sensitive to chlorpromazine and the CCCP. A K 2068 possesses efflux pump for ciprofloxacin sensitive to chlorpromazine and CCCP (Figure 2).

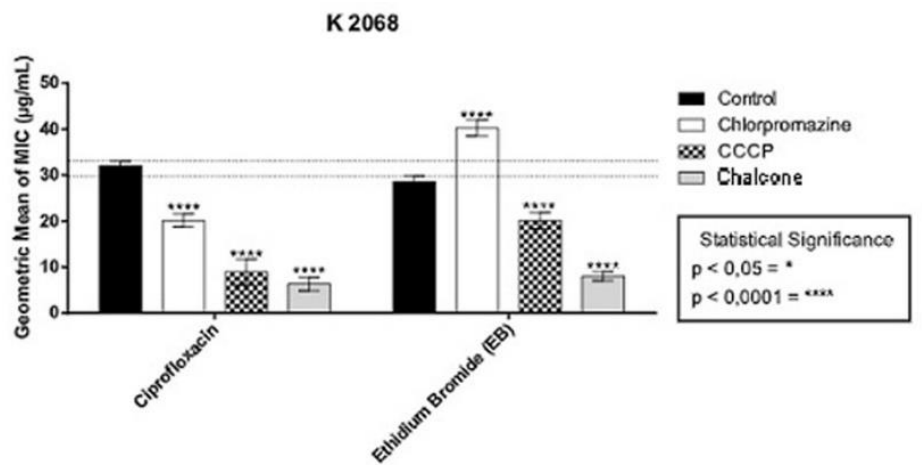

Figure 2. MICs of the Ciprofloxacin (Cip) and Ethidium Bromide (EB) in the absence or presence of the cinnamaldehyde chalcone, as well as Chlorpromazine (CPZ) and carbonylcyanide m-chlorophenyl hydrazone (CCCP) against K2068 (MepA).

The K 2068 possesses efflux pump for ciprofloxacin sensitive to chlorpromazine and CCCP (Figure 2). $\mathrm{N}$-methylation and $\mathrm{N}$-acetylation provide an increase of approximately twice in the concentration necessary to achieve 50\% inhibition of the pump causing a negative effect for NorA and MepA. In addition, phenyl ether is important for inhibition of efflux in the Mep A but not in the Nor A [33].

Previous studies showed a similar effect when the DB Thiphene chalcone was tested for the K2068 strain. DB Thiophene showed a better inhibition potential for CCCP-sensitive efflux pumps than the standard inhibitor, also acting as a strong inhibitor of efflux pumps in the Ciprofloxacin test. The inhibition mechanism was investigated by molecular docking, with the likely mechanism being an interaction with the pump, acting as a competitive inhibitor [34].

In the ethidium bromide test with strain 1199b (Figure 3), the chalcone showed the same inhibitory activities as chlorpromazine and was better than CCCP in pump inhibition. This is possibly due to the modification of the characteristic membrane of the NorA. In the 1199B strain, a chlorpromazine-sensitive pump guarantees the existence of an efflux pump since this is the only mechanism for expelling the bromide.

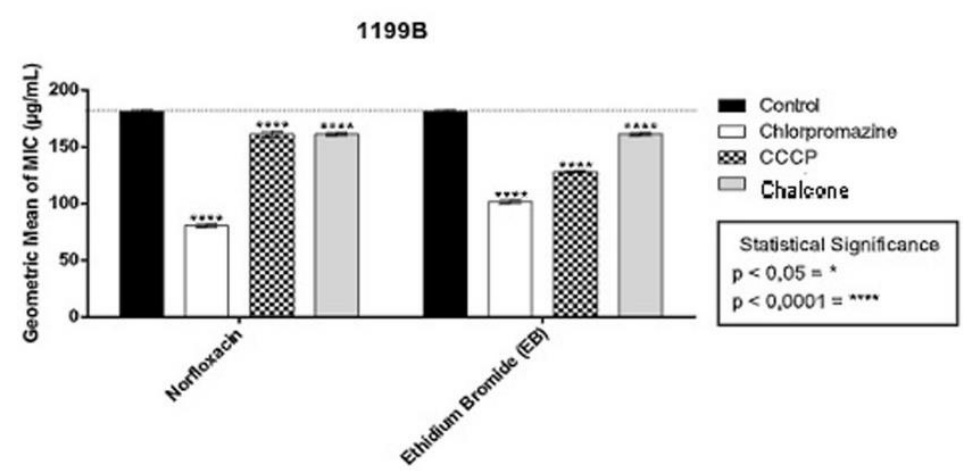

Figure 3. MICs of the Norfloxacin (NorA) and Ethidium Bromide (EtBr) in the absence or presence of the cinnamaldehyde chalcone, as well as, Chlorpromazine (CPZ) and Carbonylcyanide m-chlorophenyl hydrazone (CCCP) against SA1199-B (NorA).

In a previous study [35], inhibitory activities from 117 chalcones on NorA strains and their capacity to potentiate the activity of ciprofloxacin against ethidium bromide efflux 
mediated by the NorA on SA1199B strains were reported. From these, only twenty chalcones inhibited the pump of the tested efflux pumps, and only three of them showed synergism. Another chalcone isolated from the plant reduced by 16 times the MIC against NCTC 8325-4 strain, specific to NorA [36,37]. Structural differences regarding the ligands used and their positions in the aromatic rings between the chalcones of the tests mentioned and chalcone may have been responsible for the differences found.

\subsection{Docking results.}

To better understand the MepA inhibition mechanism of the chalcone, a docking essay was carried out using a MepA model. Figure 4 shows the best pose on the binding site of the MepA model. There are short contacts with residues Met142, Thr201, Phe153, Phe62, Tyr138, Leu59, and Phe280, as well as a hydrogen bond with Asn205. To verify if the chalcone could be a competitive inhibitor of the efflux pump, the ciprofloxacin molecule was docked against the same MepA model. The superposition of the best poses of ciprofloxacin and is shown in Figure 5. As can be seen from this figure, not only does the molecule bind to the same region of the binding site, it makes a hydrogen bond with the same residue as ciprofloxacin (Asn205). Ciprofloxacin also interacts with roughly the same residues as, in particular, Tyr138 and Met 142. As such, the chalcone could surely function as a competitive inhibitor of the MepA efflux pump.

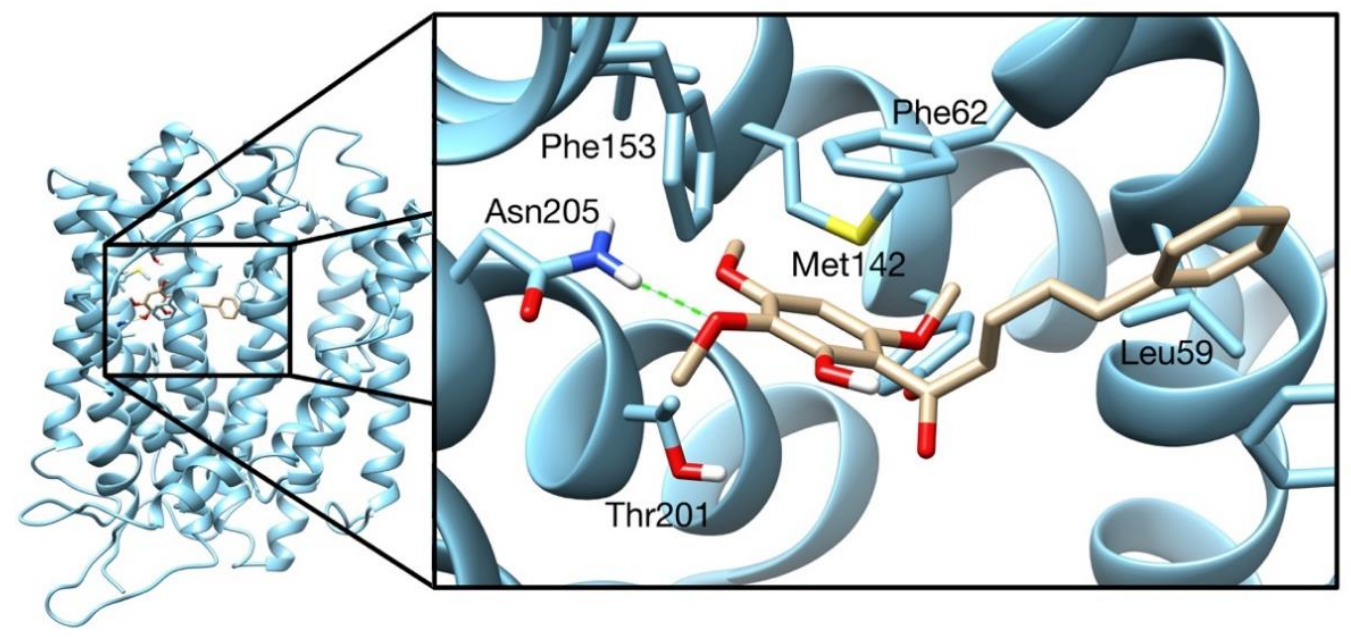

Figure 4. Best pose of the chalcone docked on the binding site of the MepA model. Hydrogen bonds are depicted in green.

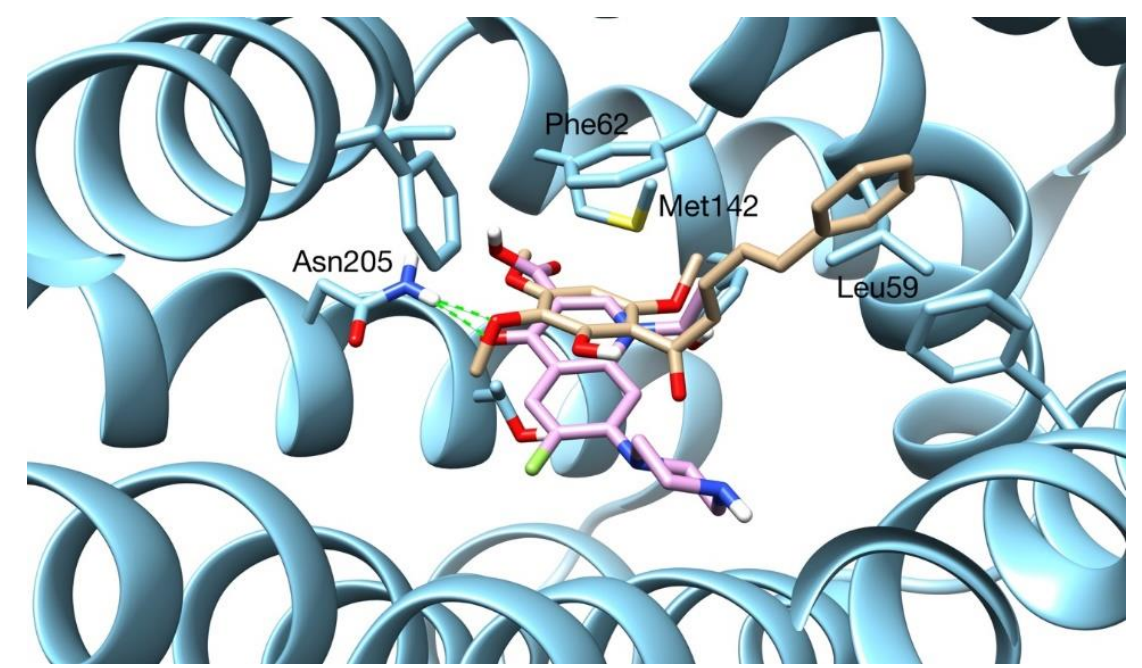

Figure 5. Superposition of the best poses of the chalcone (gold) and ciprofloxacin (pink). 


\section{Conclusions}

The NMR and infrared spectroscopic data contributed to the confirmation of the molecular structure of the chalcone derived from natural product 2-hydroxy-3,4,6 trimethoxy acetophenone isolated from $C$. anisodontus. The results of the microbiological tests showed that the chalcone could be used as a possible inhibitor of the Mep A efflux pump, also revealing that chalcone can be used as a base for the design of substances with antibiotic modifying activity. Although when associated with 1199B, it was able to potentiate the action of Cip against MDRS of K2068. The combined action of EPI and antibiotics as their substrates can keep a higher percentage of drugs within the cell, making existing anti-staphylococcal agents more effective.

\section{Funding}

This research was funded by PQ/BPI-FUNCAP (Grant\#: BP4-0172-00075.01.00/20) and CNPq (Grant: 305719/2018-1).

\section{Acknowledgments}

The authors thank FUNCAP, CAPES, CNPq, and CENAUREMN - Centro Nordestino de Aplicação e Uso da Ressonância Magnética NuclearConflicts of Interest.

\section{Conflicts of Interest}

The authors declare no conflict of interest.

\section{References}

1. Islam, A. A. A.; Jukka, P.M.; Celine, M.L.; Prasanna, N. Trans-Cinnamaldehyde Attenuates Enterococcus faecalis Virulence and Inhibits Biofilm Formation. Antibiotics 2021, 10, 702, https://doi.org/10.3390/antibiotics10060702.

2. Amalaradjou, M.A.; Narayanan, A.; Baskaran, S.A.; Venkitanarayanan, K. Antibiofilm Effect of Transcinnamaldehyde on Uropathogenic Escherichia coli. J. Urol. 2010, 184, 358-363, https://doi.org/10.1016/j.juro.2010.03.006.

3. Yuan, W.; Yuk, H.G. Effects of Sublethal Thymol, Carvacrol, and Trans-cinnamaldehyde Adaptation on Virulence Properties of Escherichia coli O157:H7. Appl. Environ. Microbiol. 2019, 85, e00271-19, https://doi.org/10.1128/AEM.00271-19.

4. Jia, P.; Xue, Y.J.; Duan, X.J.; Shao, S.H. Effect of Cinnamaldehyde on Biofilm Formation and sarA Expression by Methicillin-resistant Staphylococcus aureus. Lett. Appl. Microbiol. 2011, 53, 409-416, https://doi.org/10.1111/j.1472-765X.2011.03122.x.

5. Kot, B.; Sytykiewicz, H.; Sprawka, I.; Witeska, M. Effect of Trans-cinnamaldehyde on Methicillin-resistant Staphylococcus aureus Biofilm Formation: Metabolic Activity Assessment and Analysis of the Biofilmassociated Genes Expression. Int. J. Mol. Sci. 2019, 21, 102, https://dx.doi.org/10.3390\%2Fijms21010102.

6. Albano, M.; Crulhas, B.P.; Alves, F.C.B.; Pereira, A.F.M.; Andrade, B.; Barbosa, L.N.; Furlanetto, A.; Lyra, L.; Rall, V.L.M.; Júnior, A.F. Antibacterial and Anti-biofilm Activities of Cinnamaldehyde against $S$. epidermidis. Microb. Pathog. 2019, 126, 231-238, https://doi.org/10.1016/j.micpath.2018.11.009.

7. He, Z.; Huang, Z.; Jiang, W.; Zhou, W. Antimicrobial Activity of Cinnamaldehyde on Streptococcus mutans Biofilms. Front. Microbiol. 2019, 10, 2241, https://doi.org/10.3389/fmicb.2019.02241.

8. Chang, S.T.; Chen, P.F.; Chang, S.C. Antibacterial Activity of Leaf Essential Oils and Their Constituents from Cinnamomum osmophloeum. J. Ethnopharmacol. 2001, 77, 123-127, https://doi.org/10.1016/S03788741(01)00273-2. 
9. Ferro, T.A.; Araújo, J.M.; Dos Santos Pinto, B.L.; Dos Santos, J.S.; Souza, E.B.; da Silva, B.L.; Colares, V.L.; Novais, T.M.; Filho, C.M.; Struve, C.; et al. Cinnamaldehyde Inhibits Staphylococcus aureus Virulence Factors and Protects against Infection in a Galleria mellonella Model. Front. Microbiol. 2016, 7, 2052, https://doi.org/10.3389/fmicb.2016.02052.

10. Ali, I.A.A.; Cheung, B.P.K.; Matinlinna, J.; Lévesque, C.M.; Neelakantan, P. Trans-cinnamaldehyde Potently Kills Enterococcus faecalis Biofilm Cells and Prevents Biofilm Recovery. Microb. Pathog. 2020, 149, 104482, https://doi.org/10.1016/j.micpath.2020.104482.

11. Kim, Y.G.; Lee, J.H.; Kim, S.I.; Baek, K.H.; Lee, J. Cinnamon Bark Oil and Its Components Inhibit Biofilm Formation and Toxin Production. Int. J. Food Microbiol. 2015, 195, 30-39, https://doi.org/10.1016/j.ijfoodmicro.2014.11.028.

12. Topa, S.H.; Subramoni, S.; Palombo, E.A.; Kingshott, P.; Rice, S.A.; Blackall, L.L. Cinnamaldehyde Disrupts Biofilm Formation and Swarming Motility of Pseudomonas aeruginosa. Microbiology 2018, 164, 1087-1097, https://doi.org/10.1099/mic.0.000692.

13. Ferro, T.A.F.; Souza, E.B.; Suarez, M.A.M.; Rodrigues, J.F.S.; Pereira, D.M.S.; Mendes, S.J.F.; Gonzaga, L.F.; Machado, M.; Bomfim, M.R.Q.; Calixto, J.B.; et al. Topical Application of Cinnamaldehyde Promotes Faster Healing of Skin Wounds Infected with Pseudomonas aeruginosa. Molecules 2019, 24, 1627 , https://doi.org/10.3390/molecules24081627

14. Maria, T.A.O.; Alexandre, M.R.T.; Henrique, D.M.C.; Irwin, R.A.M.; Diniz, M.S.; Helcio, S.S.; Bruna, .M.M.; Maria, R.J.R. A.; Paulo, N.B.; Raimundo, B.F. Identification And Modulatory Activity Assessment Of 2-Hydroxy-3,4,6-Trimethoxyacetophenone Isolated From Croton Anisodontus Mull. Arg.(Euphorbiaceae), Nat. Prod. Commun. 2014, 9, 665-668. https://doi.org/10.1177/1934578X1400900520.

15. Priscila, T.S.; Jayze, C.X.;. Tiago, S.F.; Mauro, M.O.; Henrique, D.M.C.; Antonio, L.A.B.L.; Humberto, B.M.; Paulo, N.B.; Carlos, E.S.N.; Diniz, M.S.; Franqcisco, W.Q. A.N.; Emmanuel, S.M.; Hélcio, S.S.; Alexandre, M.R T. Synthesis, Spectroscopic characterization and antibacterial evaluation by chalcones derived of acetophenone isolated from Croton Anisodontus Müll.Arg.. J. Mol. Struct, 2021, 1226, 129403, https://doi.org/10.1016/j.molstruc.2020.129403.

16. Marina, M.R.S.; Paulo, T.C.F.; Beatriz, G.C.; Thiago, S.F.; Paulo, N.B.; Hélcio, S.S.; Carlos, E.S.N.; Alexandre, M.R.T.; Raimundo, L.S.P.; Jayze, C.X.; Fábia, F.C.; Cristina, R.S.B.; José, B.A.N.; Maria, M.C.S.; José, P.S.J.; Henrique, D.M.C. Aminophenyl chalcones potentiating antibiotic activity and inhibiting bacterial efflux pump. Eur J Pharm Sci. 2021, 158, 105695, https://doi.org/10.1016/j.ejps.2020.105695.

17. Jayze, C.X.; Francisco, W.Q.A.N.; Janaína, E.R.; Thiago, S.F.; Priscila, R.F.; Ana, C.J. A.; Priscila, T.S.; Carlos, E.S.N.; Paulo, N.B.; Márcia, M.M.; Emmanuel, S.M.; Nitin, K.; Antônio, C.H.B.; Henrique, D.M.C.; Murilo, S.S.J.; Hélcio, S.S.; Alexandre, M.R.T. Spectroscopic Analysis By NMR, Ft-Raman, ATRFTIR, And UV-Vis, Evaluation of antimicrobial activity, and in silico studies of chalcones derived From 2Hydroxyacetophenone. J. Mol. Struct 2021, 1241, 130647, https://doi.org/10.1016/j.molstruc.2021.130647.

18. Antonio, L.A.B.L.; Priscila, T.S.; Matheus, N.R.; Emanuelle, M.M.; Emmanuel, S.M.; Márcia, M.M.; Paulo, N. B.; Carlos, E.S.N.; Humberto, M.B.; Alexandre, M.R.T.; Hélcio, S.S. Potentiating activity of Norfloxacin by synthetic chalcones against NorA overproducing Staphylococcus aureus. Microb. Pathog, 2021, 155, 104894, https://doi.org/10.1016/j.micpath.2021.104894.

19. Javier, A.I.H.; Rodolfo, G.B.; Didier, N.R.; José, G.G.E.; David, A. M.J.; Alejandro, M.Z.; Tonatiuh, A.C.S.; Nelly, T.B.; Ricardo, A.L.M. Novel Compounds Based on Chalcone- and Pyrazoline-DIM Hybrids as Inhibitors of Staphylococcus aureus, Synthesis, DFT Studies, Biological Evaluation and Docking Studies $J$. Mol. Struct 2022, 1249, 131499, https://doi.org/10.1016/j.molstruc.2021.131499.

20. Magaly, G.A.; Raoni, S.B.G.; Camilo, H.S.L.; Fernanda, L.A.M.; Sérgio, P. M.; Laudicéa, N.O.; Talis, U.S.; Solange, M.S.V.W. Crystal structures, DFT calculations and Hirshfeld surface analysis of two (E)-3-(aryl)1-(naphthalen-1-yl)prop-2-en-1-one chalcone derivatives, potential Mycobacterium tuberculosis Enoyl ACP reductase (InhA) inhibitors and optical materials: conformational differences within the prop-2-en-1-one unit. J. Mol. Struct 2021, 146, 131091, https://doi.org/10.1016/j.molstruc.2020.128652.

21. Poonam, R.; Singh, R.N.; Alok, R.; Anshu, G.; Sweta, T.; Mukesh, K. Study of antimicrobial and antioxidant activities of pyrrole-chalcones. J. Mol. Struct 2021, 1228, 129483, https://doi.org/10.1016/j.molstruc.2020.129483.

22, Rizwan, A.; Manish, R.; Shama, Y.; Amaduddin.; Shahzad, K.; Mohammad, A.; Khan, M.S.; Rahisuddin. Facile synthesis of chalcone derivatives as antibacterial agents: Synthesis, DNA binding, molecular docking, DFT and antioxidant studies. J. Mol. Struct 2020, 1208, 127905, https://doi.org/10.1016/j.molstruc.2020.127905. 
23. Elecia, J.H.; Susan, J.B.; Pauline, G.; Michel, C.; Jonh, P.C. Ferrocenyl chalcone derivatives as possible antimicrobial agents, J. Antibiot. 2020, 73, 299-308, https://doi.org/10.1038/s41429-020-0280-y.

24. Twinkle, A.R.; Leenaraj, D.R.; Zoran, R.; Arunsasi, B.S.; Bright, K.C.; Reshma. R. Ferrocenyl chalcone derivative (E)-3-(2-methylpyrimidin-5-yl)-1-ferroceynlprop-2-en-1-one: Synthesis, Structural analysis, Docking study and their Antibacterial evaluation. J. Mol. Struct 2020, 1210, 128049 , https://doi.org/10.1016/j.molstruc.2020.128049.

25. Marwa, N.N.; Tarek, A.F.; Saleh, A.; Mohammed, M.E.; Doaa, F.D.; Fathy, H.Multi-sensing response, molecular docking, and anticancer activity of donor-acceptor chalcone containing phenanthrene and thiophene moieties. J. Mol. Struct 2021, 1240, 130581, https://doi.org/10.1016/j.molstruc.2021.130581.

26. Nirmala, G.; Kumar, E. P.; Prashanth, K.K.; Shravani, P.; Sree, K.S.; Subhashini, N.J.P. Synthesis, biological evaluation and molecular docking studies of novel 1,2,3-triazole tethered chalcone hybrids as potential anticancer agents. J. Mol. Struct $\mathbf{2 0 2 0}$, 1217, https://doi.org/10.1016/j.molstruc.2020.128356.

27. Chen, Yau-Hung.; Wei-Hua, Wang.; Yun-Hsin, Wang.; Zi-Yu, Lin.; Chi-Chung, Wen.; Ching-Yuh, Chern. Evaluation of the anti-inflammatory effect of chalcone and chalcone analogues in a zebrafish model. Molecules 2013, 18, 2052-2060, https://doi.org/10.3390/molecules18022052.

28. Taofeek, O.A.; Musa, T.Y.; Adenike, T.O.; Electrophilic And Reactive Oxygen Species Detoxification Potentials Of Chalcone Dimers Is Mediated By Redox Transcription Factor Nrf-2, J. Biochem. Mol. Toxicol. 2014, 28,11-22, https://doi.org/10.1002/Jbt.21517.

29. Waterhouse, A.; Bertoni, M.; Bienert, S.; Studer, G.; Tauriello, G.; Gumienny, R.; Heer, F.T.; de Beer, T.A.P.; Rempfer, C.; Bordoli, L.; Lepore, R.; Schwede, T. () SWISS-MODEL: homology modelling of protein structures and complexes. Nucleic Acids Res. 2018, 46,296-303, https://doi.org/10.1093/nar/gky427.

30. Trott, O.; Olson, A.J. AutoDock Vina: Improving the speed and accuracy of docking with a new scoring function, efficient optimization, and multithreading. $J$ Comput Chem 2010, 31,455-461, https://doi.org/10.1002/jcc.21334.

31. Kaatz, G.W.; Moudgal, V.V.; Seo, S.M.; Kristiansen, J.E. Phenothiazines and Thioxanthenes Inhibit Multidrug Efflux Pump Activity in Staphylococcus aureus. Antimicrob. Agents Chemother. 2003, 47,719, https://doi.org/10.1128/AAC.47.2.719-726.2003.

32. Lima, W.G.; Ramos-Alves, M.C.; Soares, A.C. Dos distúrbios psiquiátricos à antibioticoterapia: reposicionamento da clorpromazina como agente antibacteriano. Rev. Colomb. Cienc. Quím. Farm., 2019, 48, 5-28,. https://doi.org/10.15446/rcciquifa.v48n1.80062.

33. Francoise, V.B.; Jean-Marie, P.; Ving, J.L. Inhibitors of Bacterial Efflux Pumps as Adjuvants in Antibiotic Treatments and Diagnostic Tools for Detection of Resistance by Efflux. Recent Pat Antiinfect Drug Discov. 2006, 1,157-175, https://doi.org/10.2174/157489106777452692.

22. Wei, P.; Kaatz, G.W.; Kerns, R.J. Structural differences between paroxetine and femoxetine responsible for differential inhibition of Staphylococcus aureus efflux pumps. Bioorg Med Chem Lett 2004,14, 3093-3097, https://doi.org/10.1016/j.bmcl.2004.04.018.

34. Wei, H.; Zhang, X.; Wu, G.; Yang, X.; Pan, S.; Wang, Y.; Ruan, J. Chalcone derivatives from the fern Cyclosorus parasiticus and their anti-proliferative activity. Food Chem. Toxicol. 2013, 60, 147-152, https://doi.org/10.1016/j.fct.2013.07.045.

35. Holler, J.G.; Slotved, H-C.; Mølgaard, P.; Olsen, C.E.; Christensen, S.B. Chalcone inhibitors of the NorA efflux pump in Staphylococcus aureus whole cells and enriched everted membrane vesicles. Bioorg. Med. Chem. 2012, 20, 4514-4521, https://doi.org/10.1016/j.bmc.2012.05.025.

36. Belofsky, G.; Percivill, D.; Lewis, K.; Tegos, G.P.; Ekart, J. Phenolic Metabolites of Dalea versicolor that Enhance Antibiotic Activity against Model Pathogenic Bacteria. J. Nat. Prod. 2004, 67, 481-484, https://doi.org/10.1021/np030409c.

37. Rezende-Júnior, L.M.; Andrade, L.M.d.S.; Leal, A.L.A.B.; Mesquita, A.B.d.S.; Santos, A.L.P.d.A.d.; Neto, J.d.S.L.; Siqueira-Júnior, J.P.; Nogueira, C.E.S.; Kaatz, G.W.; Coutinho, H.D.M.; Martins, N.; da Rocha, C.Q.; Barreto, H.M. Chalcones Isolated from Arrabidaea brachypoda Flowers as Inhibitors of NorA and MepA Multidrug Efflux Pumps of Staphylococcus aureus. Antibiotics 2020, 9, 351, https://doi.org/10.3390/antibiotics9060351. 